\title{
A Retrospect of the Studies of Traditional Chinese Translation Theory in China in the Past Forty Years: Mainly with Reference to the Mainland of China
}

\author{
By Xiaonong Wang*
}

\begin{abstract}
Before the year 1978, in the mainland of China, there had been few attempts to study traditional Chinese translation theories. From 1978 when China began to pursue the national policy of reform and opening-up, the mainland of China saw three stages of the traditional Chinese translation theory (TCTT) studies: collection of the TCTT resources, argumentation for and affirmation of its contemporary value, and full swing studies with its modern interpretation as the main thrust. Troubled by the problems with itself, TCTT has entered its late phase of development, but as an object of interpretation, it will always be of great value. In China's map of the TCTT studies today are five major domains which are advancing simultaneously, i.e. studies of its contribution to the construction of China's new Translation Studies as a discipline and of the world's Translation Studies as a general discipline; of its systematic interpretation; of translation theorists; of some specific aspects of it; and of TCTT and Western translation theories in comparison. Some achievements therein have been translated into English and published abroad. It is suggested that in future more efforts be made for compiling a history of TCTT in its true sense, furthering its modern transformation, integrating Chinese and Western translation theories better; applying new approaches to studying TCTT and probing a meta-theory for its studies, and translating more classical texts and relevant research achievements into other languages for more productive academic exchange with foreign scholarship.
\end{abstract}

Keywords: Traditional Chinese translation theory, Translation studies, Interpretation, Transformation

\section{Introduction}

China boasts a long history of translation theory. According to Wang Hongyin (2018: 176), whatever theory on translation has appeared in China's sphere of learning before the establishment of the modern Chinese translation theory informed by modern linguistics belongs to the category of the translation theories in Chinese tradition in a broad sense. Before late 1970s, though some Chinese scholars touched on traditional Chinese translation theory (hereinafter called "TCTT" for short), what they were interested in was mainly the practical side of translation and what they did was not academic studies of TCTT in the true sense. In fact, it was not until after 1978 when China began to pursue the policy of reform and opening-up to the outside world that Chinese academia started to make efforts for studying TCTT in a relatively thorough and systematic way (Xu Jun 2018: 2). Actually, that was a new dimension of effort by a group of Chinese translation scholars in China's translation community to address translation theory issues in the face of the increasing momentum of introducing Western translation theories into China. What were done first were collection, compilation, annotation,

*Professor and MA Supervisor, School of Foreign Languages, Ludong University, China. 
and initial study of the TCTT resources, which constituted the first stage of the TCTT studies in the mainland of China. In the ten years from 1987 to 1997, the issue most often debated among Chinese translation scholars was the relationship between inheriting TCTT and introducing Western translation theories (Guo Jianzhong 1999). The introduction of Western translation theories broadened the vision of the domestic translation community and at the same time caused doubts of the value of TCTT on the part of some Chinese scholars, entailing a series of heated debates on how to treat TCTT. Since late 1990s, the value of TCTT was recovered and an increasing number of Chinese scholars began to engage in studying it, reporting more and more academic achievements. Thus, the studies of TCTT entered the second stage of transition. 2003 saw the publication of $A$ Critique of Translation Theories in Chinese Tradition: From Dao'an to Fu Lei 中 国传统译论经典诠释: 从道安到傅雷 by Wang Hongyin, which was China's first monograph devoted to a systematic study of TCTT. In view of what it achieved and the influence after its publication on the development of the translation studies in China, it marked the beginning of the third stage: conducting historic evaluation, theoretical explanation, and creative modern transformation of TCTT in a comprehensive and systematic manner.

\section{Collection of Traditional Chinese Translation Theory Resources}

China is a country with a long translation tradition rich in theoretical resources. Since Eastern Han Dynasty (25-220) when Buddhism was introduced via translation, a large amount of discourses on translation has been accumulated, which constitute the TCTT resources. As a precondition for systematic study of TCTT, first of all, those resources should be collected, compiled, and annotated. It is after 1980 that such efforts began to be made. 1984 was an important year, for it witnessed the publication of two collections of TCTT resources, one of which was A Collection of Essays in Studies on Translation 翻译研究论文集 compiled by Editorial Department of Translators' Notes (predecessor of Chinese Translators Journal 中国翻译), and the other, An Anthology of Essays on Translation 翻译论 集 compiled by Luo Xinzhang. The former is more concerned with theoretical pursuit of translation issues in modern China, while the latter, with a relatively complete collection of textual materials of TCTT. In 1992, Chen Fukang's A Draft History of Chinese Translation Theory 中国译学理论史稿 came out in the form of a history of Chinese translation theory for the first time, which marked the beginning of compiling an independent history of Chinese translation theory.

\section{Collection and Compilation of TCTT Resources}

Luo's An Anthology of Essays on Translation made groundbreaking contribution to collection and compilation of TCTT resources. It collects materials from 18 book-form works published from 1932 to 1981 and the essays included in it come from various journals and magazines. Besides, it offers an appendix which gathers a big number of achievements by preceding scholars as well as much 
relevant literature. This appendix displays Luo's scholarly vision and his innovation in the writing style. In the preface he wrote for the anthology, "A System of Its Own: Our Country's Translation Theories" 我国自成体系的翻译 理论, he divides the history of TCTT since late Eastern Han Dynasty into three stages: The stage from late Eastern Han Dynasty (25 BC - AD 220) to the middle of twentieth century (the beginning of modern China), the stage from then to the May Fourth Movement (1919), and the stage after the founding of People's Republic of China. According to him,

Over the past one thousand and more years, thanks to tremendous efforts made by numberless translators and translation theorists, namable or unnamable, a system of translation theory with the unique features of our country has been formed... Thereby, the four fundamental concepts, i.e. anben (following the source) - qiuxin (seeking faithfulness) - shensi (striving for likeness in spirit) - huajing (pursuing the ultimate realm of transformation), are both independent of and interrelated with one another, which have developed gradually one by one to form a hierarchical system. (Luo Xinzhang 1984: 18-19)

Luo's anthology has become a "must read" to TCTT researchers and been acclaimed as the "Bible" to Chinese translation community (Huang Yanjie 2015). It has been an important reference to scholars at home and abroad who engage in studying TCTT and Chinese history of translation. For example, in the 16 articles published by Meta in its 1999 special issue "The Theory and Practice of Translation in China", 9 cited materials from the anthology. Of the 8 articles published by Translator in its 2009 special issue "Chinese Discourses on Translation", 4 cited materials from it, and the reviewed book in "Revisiting the Classics" of the issue was Luo's anthology. According to Wang Hongyin (2018: 236),

By compiling An Anthology of Essays on Translation, Luo Xinzhang made contributions. First, he tried his best to gather as many as possible the essays and other materials on translation in Chinese tradition, which constituted a bank of theoretical resources and supplied the basic texts for future studies of traditional Chinese translation theory. Second, he provided a large amount of necessary literature which was relatively systematic, including relevant literature on specific topics and an index of publications (books, essays, and articles), which facilitated other scholars' studies in the domain. Third, in a display of strong sense of history and of discipline, he presented his own opinion, accurate and systematic, on Chinese translation theory, particularly on traditional Chinese translation theory, which laid foundation for further studies.

Besides, Luo was the first scholar to advocate in definite terms the construction of China's translation theory unique with its own features, with a theoretical system of its own, which would, hopefully, stand eminent and distinctive in the translation arena of the world. In 2009, a revised edition of the anthology was published with some renewal in its contents. 


\section{Compilation of the History of Chinese Translation Theory}

If we regard TCTT an integral part of Chinese history of translation, our indepth understanding of the former is inseparable from a systematic collection and compilation of the resources concerning the latter. Up to now, the most representative herein is the series of works compiled by Ma Zuyi. Since the beginning of the new century, Chinese translation scholars have paid attention to collection and collation of historical materials concerning translation and meanwhile reviewed Chinese history of translation and studied its translation phenomena from the perspectives of historiography, sociology, and anthropology (Xu Jun and Mu Lei 2009). For example, A Brief History of Translation in China and the West 中西翻译简史 (Xie Tianzhen 2009), from the viewpoint of cross reference and mutual identification, puts the Chinese and the Western history of translation in comparison, which represents a new attempt.

The work which claims to be a history of Chinese translation theory is Chen Fukang's A Draft History of Chinese Translation Theory (1992), and it gives a systematic and pertinent introduction of the past and present Chinese translation theories, with his brief commentaries on each of them, displaying his fair evaluation and original insight. Reviewing Luo's theoretical proposition and Ma's historical division, Chen inherits some views of theirs and offers his own division of TCTT. In 2000, a revised and enlarged edition of the book came out. According to Chen (2000: ii-iii), the reasons why he wrote the book are fourfold: to reveal historical facts and answer theoretical questions; to meet the need of teaching; to conduct translation studies; to elevate theoretical accomplishments. Zhao Xiuming (1996) is of the opinion that Chen makes an excellent collection of relevant literature, and though the preceding scholars did not elaborate on their theories, they put forth the propositions which are valuable to the construction of an independent and scientific system of Chinese translation theory, calling for contemporary efforts to tap their great potentials. So the significance of his work lies mainly in its justification of that construction and the foundation it lays for it. Nevertheless, Chen's work can not deserve the title of a history of Chinese translation theory in its true sense. Strictly, an ideal history of Chinese translation theory presupposes not only an accumulation of the achievements made in studying many a specific theory but also an understanding of the general spirit of Chinese translation theories, which is indispensable especially when we attempt to understand and grasp the essence of them as a whole in a thorough and coherent way.

As far as the available Chinese translation histories and translation theory histories go, the fundamental problem is their deplorable inconsistency in compiling styles, inadequate choice and indiscriminate use of raw materials, and deficiency in probing into the development of the translating skills in the domain and the inheriting relationship between them. Their compilation of the history of practice and that of theory are actually mixed, which betrays their confusion of the two sides, the want of effective labour division in studies between them, and the 
somewhat jumbled results of the studies. Therefore, to write an ideal history of Chinese translation theory, much more efforts need to be made.

\section{Theoretical Interpretation of Traditional Chinese Translation Theory}

As mentioned above, during the ten years between 1987 and 1997, one of the major issues debated among Chinese translation scholars was the relationship between inheriting TCTT and introducing Western translation theory. Before the arrival of the new century, a basic consensus regarding the contemporary relevance of TCTT had been reached in the Chinese translation community. In their review of the 2006 translation studies in China, Mu Lei and Wang Binhua (2007) pointed out that inheriting TCTT was indispensable to the construction of China's modern translation theory and the studies of TCTT were actually conducted in the process of that construction. After the beginning of the new century, the domestic studies of TCTT entered the stage of theoretical interpretation ( $\mathrm{Li}$ Linbo 2006). Its evidence can be found in the increasing number of academic papers in the field; the deeper research themes in a widened scope (i.e. comprehensive and overall assessment of TCTT, analysis of the thinking features, stating manners, logical paths, cognitive modes, and internal systems characterizing TCTT); more elaborate exploration into the major issues concerning TCTT and its concepts and categories; more academically standardized ways of citing sources and reporting research results; more diversified research methods and perspectives (Zhao Wei 2014). In the following sub-sections, a brief review will be made of the achievements reported by the academic circle in the mainland of China in TCTT studies and then the representative works therein will be discussed.

\section{Major Topics and Domains of TCTT Studies}

In the twenty years from 1978 to 1998 , according to incomplete statistics, the numbers of articles published in various periodicals, of the monographs, and of anthologies with regard to translation reached over 14 thousands, about 500, and 20-odd, respectively (Guo Jianzhong 1999). Most of these publications are concerned with studies of TCTT. Since 2000, there have been also many articles and monographs devoted to TCTT studies. By entering the Chinese characters 中 国传统译论 as the search words into CNKI, we can get over 100 academic papers published in the indexed periodicals before and in 2017 (book reviews and general reviews not included), which can reflect the basic picture of TCTT studies in contemporary China. These reported achievements can be roughly classified into five domains of TCTT studies, each of which the writer will survey briefly below.

$\underline{\text { Studies of TCTT in relation to construction of Translation Studies as a discipline }}$

The relation between TCTT and the construction of Translation Studies as a discipline has made an important topic for TCTT studies. Liu Zhongde (2000) 
evidences the remarkable achievement and sustainable development of Chinese scholarship in TCTT studies by presenting many facts. According to Zhang Boran and Zhang Sijie (2001), the core theories on translation shall be well grounded on the essence of Chinese language and culture by exploring and inheriting the advantages of traditional theories on translation while doing away with the disadvantages thereof, so as to bring about a new pattern of translation theory which blends the essence of Chinese cultural heritage and Western research methods for translation studies, and manifests the spirit of the times. Wang Hongyin and Liu Shicong (2002) point out that Chinese translatology can be regarded as a logical development of the evolution of traditional Chinese translation theories and a natural outcome of the historical development of the Chinese translation tradition, and to contribute to the growth of translatology in China, a translatology with a theoretical system and a modern form of discourse, efforts should be made to reinterpret, in a scientific and vigorous manner, major traditional Chinese translation theories so that they can be transformed into the central components of modern Chinese translatology. At the end of the last century, the domestic translation community reached a consensus on the significance of TCTT studies to and its role in building Chinese Translation Studies and set about more thorough and deep-going explorations.

After the beginning of the new century, two issues in this domain have attracted much scholarly attention. One is the assessment of the status quo of TCTT studies and the orientation of future academic efforts therein, and the other is the spread of TCTT via teaching. Li Linbo (2006) holds that the domestic studies of TCTT has entered the stage of its modern interpretation and in future more such interpretation efforts should be made to merge its valuable thoughts and viewpoints into the construction of modern Chinese translation theory so as to maintain the humanistic-scientific coordination in it. Wang Hongyin (2008) probes TCTT by situating it in the broad vision of the new translation studies and, through comparative analysis of the common ground and difference between the Western and the Chinese tradition of scholarship, discusses the basic approach to innovative integration of Chinese and Western translation theories and its prospects. As a recently reported research result, Fang Mengzhi (2017), informed by statistics, argues that Chinese translation scholars are weak in theoretical originality, and, liable to employ a Westernized system of discourse, they lack their own means of discoursing translation, which fail to match the status of China as a large country in terms of translation, so he emphasizes that China should create her own system of translation discourse. Regarding the issue of inheritance and spread of TCTT via translation textbooks, Tao Youlan (2015) holds that not only the pace of translating classical TCTT texts should be quickened, but also more efforts should be made to teach TCTT on the university level. In the opinion of Fu Jingmin and Yuan Limei (2017), the systematization of Chinese translation theory should go beyond the theoretical construction on the macro level and, with translation practice and teaching as the fundamental basis, the studies on the middle and micro level should be intensified to build the integrated system of translation studies with productive macro, middle, and micro interaction. 
$\underline{\text { Studies of the entirety of TCTT and its interpretation }}$

According to Wang Hongyin (2018: 180-181), the modern interpretation of TCTT should aim to fulfill the theoretical tasks on three levels, i.e. categorizing the TCTT issues; interpreting the significance of TCTT, and transforming the forms of TCTT. Wang Hongyin's monograph A Critique of Translation Theories in Chinese Tradition: From Dao'an to Fu Lei ([2003] 2017; English edition 2018) is the representative achievement in this domain, which are mainly concerned with historical evaluation, theoretical judgment, and creative transformation of TCTT. Cheung Martha (2008), from the perspective of promoting Chinese and international translation studies, points out the importance of re-reading and interpreting TCTT. As Pan Wenguo (2012) advocates, one of the paths for constructing translation theory with Chinese characteristics is to get free from the Western approach and return to the Chinese tradition in pursuit of Chinese translation discourse. In recent years, the studies in this regard emphasize how to integrate TCTT studies into the construction of modern Chinese translation theory. In regard to how to inherit TCTT, Zeng Lisha (2017) argues for an approach to integrating and constructing the open system of theoretical categories. Cheng Yongsheng (2017) is of the opinion that TCTT is replete with modern translation theory elements, yet they are yet to be re-read and re-written for systematic theoretical construction, which may lead to the modern Chinese translation theory.

In the several major dictionaries of translation studies compiled by Chinese scholars are entries devoted to TCTT, such as A Dictionary of Translation Studies in China 中国译学大辞典 (Fang Mengzhi 2011), where its entry of TCTT contains 57 sub-entries, indicating the rich accumulation of the TCTT studies in China, which deserves our affirmation and attention. Other significant themes include the studies concerning the historical division of the TCTT development and classified studies thereof (e.g. Jiang Tong 1999; Zhu Zhiyu and Zhang Xu 2009); studies of the overall features of TCTT (e.g. Wang Xiaonong 2006); studies of cultural sources of TCTT (e.g. Zhu Yu 2008; Wei Jian'gang 2015); studies of TCTT terms and concepts (e.g. Kong Xiangli 2013). Recent years saw some scholars' attempt to construct certain systems of TCTT, such as Guo Jianzhong (2015), who, on the basis of the principle of system theory, tries to set up a TCTT system comprising ten sub-systems at different levels.

\section{$\underline{\text { Studies of translation theorists }}$}

In the past four decades, the studies of Chinese translators past and present made an important domain in the map of TCTT studies in China. Those most often visited are Zhiqian (c. fl. 3rd century), Dao'an (314-385), Kumarajiva (334413), Yancong (557-610), Xuanzang (602-664), Ma Jianzhong (1845-1900), Yan $\mathrm{Fu}$ (1864-1921), Lin Yutang (1895-1976), Zeng Xubai (1895-1994), Jiao Juyin (1905-1975), Jin Yuelin (1895-1984), He Lin (1902-1992), and Qian Zhongshu (1910-1998). Of them, Yan Fu attracted the greatest scholarly attention and the studies of Yan will be surveyed below as an illustration in this regard. 
The past Yan Fu studies were concentrated on his trio of xin (faithfulness), $d a$ (communicability), and $y a$ (elegance) as the desiderated translation criteria. Actually, the number of publications concerning Yan and his translation discourse is very big. Here we only cite a few examples. According to $\mathrm{Xu}$ Jun, in China the studies of Yan's trio has never stopped and many translation scholars in other countries know Yan's trio and tend to take it as the thought representative of TCTT (Tao Lichun 2016). Wang Hongyin's initial achievement in making modern interpretation and transformation of Yan's trio is found in his A Comprehensive Coursebook of English-Chinese Translation 英汉翻译综合教程 (1989). Shen Suru, in his On Xindaya: Research on Yan Fu's Translation Theory 论信达雅一 一严复翻译理论研究 (1998) collects over a hundred scholars' discourses on Yan's trio and summarizes them.

Wang Hongyin (2017) reflects on Chinese scholars' studies of Yan's trio and classifies them into three schools: subscribers, opponents, and modifiers. $\mathrm{He}$ further divides those subscribers into recognizers of his influence (e.g. Chen Fukang 1992), of his system (e.g. Chen Quanming 1997), of his theoretical value (e.g. Xu Jun 1998), and of the tradition he established (e.g. Liu Miqing 1993); those opponents into rash deniers (e.g. Huang Yushi 1988), multiple-aspect doubters (e.g. Feng Shize 1994), partial-content negators (e.g. Zhang Yinglun 1988), deniers of it as something historical (e.g. Jin Di 1988); those modifiers into partial-content modifiers (e.g. Liu Zhongde 1991) and substitute proposers (e.g. Huang Yaomian 2012). According to his comments, (1) Whether completely negating Yan's trio or denigrating it as beneath attention, or blindly following it or even theoretically elevating it boundlessly, all these are extreme views, which are harmful in practice and childish in theory; (2) Whether affirming its historical contribution, or believing its depth and profundity in its cultural source, or attributing its origin to the East or the West, all these cannot be the reason or excuse for affirming or denying its theoretical value, and furthermore, cannot replace the theoretical analysis of it and the effort to reconstruct it ideologically; (3) As a translation theory, his trio does not occupy the position of or constitute a complete system of theory, for it is at most an exposition of what can be called "translation criterion" in TCTT. Any attempt to overstate it and regard it as the whole translation theory, or to think that it does not reach what the capacity of a translation theory requires and then deny it, is not right; (4) As a translation criterion, his trio makes a small system, with its own construction mode and complete meaning. To think that it divides one (xin) into three (xin-da-ya), or that the three $(x i n-d a-y a)$ can be boiled down to one (xin), does not conform to what Yan intended to mean and goes against what the method of scientific research calls for; (5) The $x i n, d a$, and $y a$ were originally rooted in the rhetoric theory in Chinese tradition, but Yan converted them to the categories of translation theory. This conversion can be inspirational to constructing the new Chinese translation theory, thus calling for our earnest effort to study its theoretical significance and the rationality of building the translation theory on the basis of the rhetoric theory. To refuse that inspiration is unwise (Wang Hongyin 2018: 100-101). 


\section{$\underline{\text { Studies of special aspects of TCTT }}$}

The special aspects of TCTT which have been probed often include its aesthetics (e.g. Zhang Boran \& Zhang Sijie 1997; Chen Daliang 2009; Wang Ping 2011), translational style (e.g. Wu Xianlu 2003); translating skills and criteria (e.g. Si Xianzhu 2002); translation of names and specialized terms (e.g. Guo Dan 2011; Gao Cun 2016); wen (refined)-zhi (unhewn) in Buddhist sutra translation (e.g. Zhang Chunbai 2006; Zhao Wei 2009). Of them, it is worth mentioning that some scholars distinguish the two pairs of concepts, i.e. wen$z h i$ and zhiyi (literal translation)-yiyi (free translation). For example, Wang Hongyin (2003) point out their being two different stories. In Studies in Traditional Chinese Translation Theory 中国传统译论专题研究(2009), Wu Zhijie probes theoretically the linguistic, ethical, thinking, aesthetic, and cultural aspects of translation with reference to TCTT. Some other scholars compare TCTT in different historical periods (e.g. Yang Dongmin 2007), conduct cognitive linguistics based analysis of TCTT (e.g. Wang Mingshu 2009), and make interpretation of TCTT from a perspective informed by Western translation theory (e.g. Su Yan 2008; Xie Sitian 2014).

Zhang Sijie's On the System of Categories in Chinese Traditional Translation Theories 中国传统译论范畴及其体系 (2006) is the second monograph devoted to studying TCTT after Wang Hongyin's. Besides its introduction and conclusion, its main body consists in the origin of the TCTT categories, their ontology, epistemology, and aesthetic process, the system of the categories and the paradigm implied in them. As concluded by Zhang (2006: 296-297), the paradigm underlying the system of the categories in TCTT can provide explanation for the historical rationality of the theoretical forms of TCTT, but, judging from what is required by modern scholarship, in spite of its profundity, it is too single and simple, calling for enrichment which reflects the times. According to Wang Hongyin (2018: 242), (1) Zhang broadens and deepens the previous studies on the cultural resources and philosophical foundation of TCTT and, particularly by his comparative study between Chinese and Western philosophies and introducing Western process philosophy, makes contribution to our understanding of the translation process thought implied in TCTT; (2) His analysis of the basic features characterizing traditional Chinese culture is relatively complete and deep-going, but, unfortunately, his probe into the TCTT itself is far from adequate, if not a failure to go deep into it; (3) As far as his overall inclination goes, a trouble with his study is the replacement of his translation study with his philosophical argumentation, and methodologically, his abstract argumentation and statement in content do not go straight to address his topic, so these problems affect the directness of his study and the lucidity of his expression, to the detriment of his use of a straightforward style of study and a succinct manner of writing.

The discussion of the principle and method for unifying the practices of translating names is a line running through the Chinese history of translation theory. Zhu Zhiyu and Huang Libo's Traditional Chinese Translation Theory: Studies of Name Translation 传统译论: 译名研究 (2013) is a significant achievement in studying the translation of names. It investigates almost all 
relevant Chinese discourses on name translation in the past and identifies the relationship between them with regard to inheritance, criticism and innovation. Its authors start from description and go beyond it to constructing the system of TCTT discourse for translating names (Xing Jie 2014).

\section{Comparative studies between Chinese and Western translation theory}

The studies here have been emphatic of overall comparative studies between Chinese and Western translation theories (e.g. Zou Dongqi 1991; Zhou Yan 1998; Li Zhi and Wang Zichun 2005). Some scholars, through comparative studies, present in-depth understandings of the general features of Chinese and those of Western translation theory (e.g. Tan Zaixi 1998). Li Jingmin and Xu Shuhua (2002), after analyzing the modes underlying Chinese and Western translation traditions, claim that either has its own characteristics and advantages, it is improper to judge them in terms of superiority, and the two traditions should draw on each other's strong points and bring out the best of each other. In the opinion of Zhu Guicheng (2005), the positive influence of Western translation theory on Chinese translation theory lies in broadening the vision of the latter in thinking about translation, yet the negative influence is not only its diluting Chinese translation scholars' memory of their national translation theory but also weakening the creativity of the translation theory in their national tradition, so it should be prioritized to identify the essential difference and seek productive dialogue between the two sides so as to build the original system of Chinese translation theory. Some other scholars make comparative studies of certain specific translation theories in Chinese and Western traditions (e.g. Zhao Wei \& Shi Chunrang 2005). A new trend in this domain is that some scholars have begun to review Western translation theory from the viewpoint of TCTT. For example, Wang Xiangyuan (2016), by analyzing the rich connotation of some key concepts in TCTT, finds that the Chinese concepts of translation can be contributive to the settlement of the incessant debate between translatability and untranslatability in the West.

The important book-form achievements in this domain include A History of Chinese Translation Thoughts in 20th Century 20 世纪中国翻译思想史 by Wang Bingqin ([2004] 2009); Index of Translation Studies in China 1894-2005 中 国翻译理论百年回眸 by Wen Jun (2005); Translation Theory Changes in Modern China: A Study of Literary Translation Norms in the May-Fourth Movement Period 中国近代翻译思想的嬗变一一五四前后文学翻译规范研究 by Liao Qiyi (2010); Invisibility and Visibility: From Traditional Translation Theory to Modern Translation Theory 隐身与现身: 从传统译论到现代译论 by Xie Tianzhen (2013); and Inquiries in Translation Studies 译学研究吒问录 by Zhang Boran \& Xin Hongjuan (2016).

\section{Representative Achievement in Modern Interpretation of TCTT}

In late 1980s and 1990s, there occurred among Chinese translation scholars a heated debate over the relation between inheriting TCTT and introducing Western 
translation theory, which was largely caused by the hitherto lack in systematic summarization and in-depth study of TCTT. The first monograph dedicated to studying TCTT in China was A Critique of Translation Theories in Chinese Tradition: From Dao'an to Fu Lei by Wang Hongyin (2003). Yang Zijian said in the preface he wrote for it, "Its significance to the Chinese translation studies today can never be underestimated. Particularly, with regard to the domestic studies of the translation theories in Chinese tradition, we have good reasons to say that the publication of this manuscript will mark the beginning of a new historical phase" (Wang Hongyin 2003: 2). Luo Xinzhang, in a letter to its author, said "Your interpretation of traditional Chinese translation theory in the light of modern theory breaks fresh ground, [...] With well-grounded and convincing argumentation, your work is a truly great achievement in recent translation studies" (Wang Hongyin 2017: 356). Wang's work represented an approach subscribed to by most scholars in the mainland of China to constructing Chinese Translation Studies as a discipline. In China today a tripartite pattern of the theoretical pursuit of translation has been formed, i.e. studies of TCTT, of Western translation theory, and of literary translation criticism. In such a sense, the TCTT studies has established its disciplinary status, indicating its regeneration in the new times. To all such, Wang's monograph contributed much indeed.

Wang's work is a monograph of theoretical translation studies, which aims to make a systematic review of TCTT by applying the hermeneutic method. It selects ten representative theories proposed respectively by Dao'an, Yancong, Xuanzang, Zanning, Yan Fu, Zhang Shizhao and $\mathrm{Hu}$ Yilu, He Lin, Jin Yuelin, Qian Zhongshu, and Fu Lei and analyzes them one by one by adopting a threedimensional methodology in different contexts, i.e. historical evaluation, theoretical explanation, and creative modern transformation of each theory, with regard to its basic propositions, concepts, and categories, from its classical form into a modern form. Its periodic demarcation of the translation theories in Chinese tradition take into account socio-historical conditions, academic and cultural sources, and the evolutive relationship between those theories themselves. Historical periods are divided along two lines into three ones (ancient, modern, and contemporary times) and four major ones (incipient, classical, metaphysical, and intuitive periods) respectively (with some overlapping), the former being a socio-political outward view pattern and the latter, an academic inward view pattern, which is the principal one. Having combed the historical materials, he selects ten theoretical issues including "zhi (unhewn) school and wen (refined) school", "transliteration and sense translation", "direct translation and indirect translation", "translating meaning and translating taste", "likeness in spirit and likeness in form", "translation criterion", "translatability", "realm of translation", "the translator", and "language and translation". Then he makes modern interpretation of each of them and transforms them into six theoretical issues, i.e. ontology, methodology, epistemology, criterion and principle, subjectivity, and translatability, in the modern discipline of Translation Studies. Besides, he finds out the following five theoretical issues rarely considered in TCTT: translation process, effect evaluation, stylistic correspondence, semantic conversion, and translation criticism. The main purpose of his study is to tap the heritage of 
translation theories in traditional Chinese culture and promote the theoretical transformation of their classical forms to modern ones, thus preparing conditions for formulating modern Chinese translation theory and contributing to the ultimate construction of the universal translation theory the world over.

After its publication, it brought about two positive effects in Chinese translation community. On is the direct response to it, as evidenced by the publication of several book reviews, such as Zhu Hui (in Chinese Translators Journal 2004) and Zhao Xiuming (in Journal of Foreign Languages 2004). The writer surveyed CNKI on February 1, 2016, and found the monograph had been cited 421 times by other authors in their research papers. The other is its direct stimulation of efforts for TCTT studies, which brought about a series of achievements. The new studies and discussions of TCTT aroused by its publication partly rectified the problematic wholesale Westernization in constructing Chinese translation theory, and it rallied an academic force engaging in tapping national resources for the construction of modern Chinese translation theory, which balanced that given to introducing Western translation theory and particularly the school of translation studies.

In 2017, by revising, expanding, and deepening the 2003 edition, Wang published his new two-volume Chinese edition. Volume One retains the basic framework of the principal part of his 2003 edition, with some new content added to the chapters thereof, which displays the author's efforts for refinement of his past work by theoretical improvement and offering more data. Volume Two consists of "Chinese Translation Studies Review (2000-2003)" and "Review and Renewal of Chinese Translation Theory (2003-2016)". The former epitomizes his inheriting the humanistic spirit of TCTT and pursuing theoretical construction, involving his creative conception of yibi 译笔 (the competent pen for translation) and the impressionistic approach to translation 表现手法, and his elaboration of translation criteria by drawing on traditional resources, all of which manifest his new accomplishment in studying translation theory. The latter, which is completely new, continues his probe and reports his research results he got before 2016. In this part he makes new efforts to comb relevant historical materials, identify new translation theory issues, and transforms them into new theoretical categories. Besides, he looks back into, analyzes, and comments on the historical development of TCTT. Despite different emphases, the principal parts and other parts of his work are coherent, for there is a logic running through them, that is, the origination of Chinese translation theory, criticism and inheritance of it, and new trends in the current translation studies in China.

\section{Translation of TCTT Literature and Research Results}

In the past forty years Chinese scholars published in English a number of articles concerned with the TCTT studies. As for the translation of TCTT, up to now only three anthologies were available, both mainly from the hands of Hong Kong scholars. One is Leo Tak-hung Chan's Twentieth-Century Chinese Translation Theory: Modes, Issues and Debates (published by John Benjamins Publishing Company, 2004), and the other, Martha Cheung's An Anthology of 
Chinese Discourse on Translation Volume 1: From Earliest Times to the Buddhist Project (published by St. Jerome Publishing, 2006) and An Anthology of Chinese Discourse on Translation Volume 2: From the Late Twelfth Century to 1800 (published by St. Jerome Publishing, 2017). Chan's work contains the English translations of over forty two Chinese essays on translation published in the twentieth century. Either of Cheung's two anthologies is an English translation of selected and annotated discourses of TCTT, which is of monumental significance, with the salient feature of inheriting traditional Chinese scholarly spirit and drawing on new research achievements. The only translated achievement of contemporary TCTT studies made by scholars from the mainland of China at present is the English edition of Wang Hongyin's A Critique of Translation Theories in Chinese Tradition: From Dao'an to Fu Lei. It is rendered by Wang Xiaonong from the 2017 edition and published by American Academic Press in 2018 as the achievement of the translator's national translation project supported by "Chinese Fund for the Humanities and Social Sciences". By this translation, English readers can know not only the classical literature of TCTT, the method for studying TCTT adopted by a contemporary Chinese scholar and the result he achieved, but also the developments of the TCTT studies in the past four decades. On the whole, deplorably, the number of translated works in this regard is too small.

\section{Prospects of the TCTT Studies}

Having passed nearly two thousand years, TCTT has entered into its late stage, which is mainly caused by the problems with itself. According to Wang Hongyin (2018: 184), (1) the number of its theoretical questions is small, most of which are outdated, and such questions have been discussed again and again, with nothing new brought forth, which means but a waste of time; (2) the theoretical categories are limited and not defined rigorously, which are used without adequate definition and discrimination, and they have no way to enter into new theoretical vision and get identification with the Western modern translation theory; (3) the theoretical perspective is narrow and conservative, even with some self-complacency. For example, its attention is pinned on literature, with ignorance of science; it sees only China, losing sight of the world; it does well in induction, yet failing in deduction. Thus, it is hardly possible for new thought and new method to occur in that regard. However, its termination means its regeneration in modern times. This ending process is not a natural one, for it calls for considerable efforts to be made by translation scholars for its historical assessment, theoretical judgment, and creative transformation. As the object of interpretation, TCTT will always attract our attention and will never get outdated and perish.

As indicated by the above review of China's TCTT studies in the past forty years, we know well that Chinese translation community has made remarkable achievement therein. The purpose of making studies of TCTT in China is to promote the development of Translation Studies as a discipline in the country and ultimately make Chinese contribution to constructing 
Translation Studies as a general discipline with universal significance. Today, in China, the studies of TCTT, of translation criticism, and of Western translation theories have developed as the troika in Chinese effort to construct theoretically Translation Studies as a discipline. In my opinion, as far as promoting the studies of TCTT in China in the foreseeable future is concerned, more efforts should be made in the following five aspects.

(1) To push forward the studies of TCTT as a system and of the individual theories with an aim to compile the history of Chinese translation theory in the true sense. In this regard, four points are worth special attention. One is to ensure that the history of theory and the history of practice should match each other in respect to their historical division, beginnings and endings, so that they can explicate each other. Another is to take tentatively translation criticism and method as the intermediate level so as to elucidate the relationship between theory and practice. A third one is to start from the relatively deeper studied side to explain the extent to which theory depends on practice, or vice versa. The fourth is to reveal the status and function of China's translation in the history of cultural exchange between China and the West as well as in the history of exchange between the Han Chinese ethnic group and other Chinese ethnic minority groups, and clarify the future orientation of China's translation theory and practice and the prospects of their communication and integration with other countries' translation theory and practice.

(2) To continue tapping the translation theory resources in the heritage of traditional Chinese culture so that the transformation of the ancient form of traditional scholarship into a modern form of theory can be completed and China's new translation theory can be established. Here, three issues need more scholarly attention. One is to dig deeper into the translation concepts in Chinese cultural resources and construct a new view of translation on the basis of the native thinking prototype with primitive oriental characteristics. Particularly, the traditional Chinese concepts of wenbi 文笔 and yibi 译笔 should be inherited and renewed, and, as influencing factors, they can serve as a frame of reference by which to review the entire Chinese history of translational arts. The linguisticoperation-based inheritance of wenbi and its historical progress should be clarified first. And then the concept of yibi can be applied to observing the history of literary translation or translated literature, thus revealing the mechanism of inventing and inheriting yibi. Another is, in studying translating methods, to absorb the various techniques employed in traditional Chinese arts and sharpen the awareness particularly with regard to the Chinese language transformation skills, thus improving the performance in the linguistic transformation between Chinese and other languages which covers the whole range of text types and writing styles. A third one is, in regard to translation criticism, to renew the traditional translation principles and criteria and set up a new system of more applicable and effective criteria and evaluation procedures, thus forming an advantageous domain of TCTT with literary translation and criticism as its mainstay.

(3) To deepen the mutual understanding between TCTT and modern Western translation theory by their academic interaction through explicating each other. The more urgent issues to be addressed here include: The first is, taking modern 
Western translation studies and philosophy as a frame of reference, to identify more issues in TCTT which are of theoretical value and elucidate and interpret them in a theoretically logical manner so that Chinese translation theory can be in a well-grounded position to have dialogue with the international translation community. The second is to recognize those most valuable and characteristic theories in TCTT and refine them on the basis of their basic principles so as to make up for their inadequate deductive system. Through rational deduction, they will be imbued with the explicitness featuring modern theories and the spirit of times, thus becoming a part of modern translation theory. The third is to extract concepts from the translation theories and literary theories in Chinese tradition, use them to interpret those relevant or similar concepts in modern Western translation theory, and reveal their hidden meaning, so as to form optimum combinations from Chinese and Western cultural resources. The fourth is to blend Chinese and Western academic resources, such as the advantage of traditional Chinese learning in critical interpretation of ancient texts and the Western linguistics and hermeneutics, the Chinese poetics and the Western poetics, and the traditional Chinese scholarship concerning writings and the Western philology and textual linguistics. Such blending is conducive to laying the shared foundation for the interfacing between modern Chinese and Western scholarship, which can serve as the academic resources and inspiration sources for future translation studies.

(4) TCTT, with its own value and spiritual tradition, calls for methodological and epistemological representation of them. The advance in the science of the brain nerve and consciousness and the fourth industrial revolution in brewing have brought about new opportunities for rediscovering, recognizing, and developing the system of TCTT (Wen Hui 2015). In future TCTT studies, more conscious efforts should be made to adopt new theory, method, and technique. Meanwhile, after forty years of studying, it is necessary to make meta-theoretical reflection on the hitherto TCTT studies. Therefore, it will be significant to review the achievements already made, point out their merits and demerits, and develop a meta-theory over the theoretical pursuit of TCTT studies, which will guide their development better .

(5) Under the backdrop of increasing academic exchange between China and other countries, to let more Chinese translation theories and more achievements of TCTT studies go out through translation has become of increasing importance. More efforts should be made to give play to the advantages of Chinese translation community in translating and promote China-foreign cooperation in translation and publication thereof. Thus, our colleagues in other countries will hear more voices of Chinese translation theorists, which will not only help them with a better understanding of the long tradition of the Chinese translation theory but also promote the two-way interpretation and construction between the translation theories of China and those of other countries. 


\section{References}

Chen Fukang (1992/2000) A Draft History of Chinese Translation Theory 中国译学理论 史稿. Shanghai: Shanghai Foreign Language Education Press.

Cheng Yongsheng (2017) "Modern Elements in Traditional Chinese Translation Theory: With Reference to Literal Translation and Free Translation" 我国传统译论中的现 代元素——以直译意译研究为例. Foreign Languages Research 2: 84-88.

Cheung Martha (2008) "On the Why and the How of Re-reading Traditional Chinese Discourse on Translation" 重读传统译论: 目的与课题. Chinese Translators Journal 6: 5-10.

Fang Mengzhi (2011) A Dictionary of Translation Studies in China 中国译学大辞典. Shanghai: Shanghai Foreign Language Education Press.

Fang Mengzhi (2017) "China Needs Her Own Translatological Discourse System" 翻译 大国需有自创的译学话语体系. Foreign Languages in China 5: 93-100.

Fu Jingmin, Yuan Limei (2017) "On the Translation Studies Systematization in China" 新 时期我国译学体系化的思考. Foreign Language Research 3: 80-84.

Huang Yanjie (2015) "On the Canonicity and the Canonical Construction of An Anthology of Essays on Translation" 《翻译论集》的经典性及其建构要素. Foreign Language and Literature Research 4: 60-66.

Guo Jianzhong (1999) "Translation Studies in China (1987-1997)" 中国翻译界十年 (1987-1997). Journal of Foreign Languages 6: 53-61.

Guo Jianzhong (2015) "Towards Constructing a System of Chinese Traditional Translation Theory" 进一步深入研究中国传统译论一一探索构建中国传统译论体系. Shanghai Journal of Translators 1: 1-7.

Li Jingmin, Xu, Shuhua (2002) "Approaches towards Translation Studies in China and in the West" 中西译论研究基本模式对比. Journal of Sichuan International Studies University 4: 106-108.

Li Linbo (2006) "Traditional Chinese Translation Theory: Retrospect and Prospect" 中国 传统译论的后顾与前瞻. Shanghai Journal of Translators 1: 7-12.

Liu Zhongde (2000) "On the Achievements in the Study of Chinese Traditional Translation Theories and the Construction of Translatology in China" 事实胜雄辩— 一也谈我国传统译论的成就和译学建设的现状. Foreign Languages and Their Teaching 7: 34-38.

Luo Xinzhang (1984) An Anthology of Essays on Translation 翻译论集. Beijing: Commercial Press.

Mu Lei, Wang, Binhua (2007) "A Review of the 2006 Translation Studies in China" 译学 研究发展的新成就—-2006 年译学研究综述. Chinese Translators Journal 3: 30-34.

Pan Wenguo (2012) "Translation Theory and Discourse of China" 中国译论与中国话语. Foreign Language Learning Theory and Practice 1: 1-7.

Tao Lichun (2016) "An Interview with Professor Xu Jun" 关于翻译研究的思路与重点 途径——许钧教授访谈录. Chinese Translators Journal 3: 79-82.

Tao Youlan (2015) "On a Strategic Approach to the Inheritance and Spread of Traditional Chinese Translation Theories via Translation Textbooks" 中国传统译论的战略传 承与传播——翻译教材建设视角. Shanghai Journal of Translators 4: 14-20. 
Wang Hongyin (2003) A Critique of Translation Theories in Chinese Tradition: From Dao'an to Fu Lei 中国传统译论经典诠释——从道安到傅雷. Wuhan: Hubei Education Press.

Wang Hongyin (2008) Interweaving Translation Theories in Chinese and Western Tradition into a New Horizon of China's Translatology 融通中西译论, 革新中国 译学. Foreign Languages in China 6: 33-39.

Wang Hongyin (2017) A Critique of Translation Theories in Chinese Tradition: From Dao'an to Fu Lei 中国传统译论经典诠释——从道安到傅雷. Dalian: Dalian Maritime University Press.

Wang, Hongyin (2018) A Critique of Translation Theories in Chinese Tradition: From Dao'an to Fu Lei. Translated by Wang Xiaonong. Salt Lake City, USA: American Academic Press.

Wang Hongyin, Liu Shicong (2002) "Modern Interpretation of Traditional Chinese Translation Theory: Towards the Construction of Translatology". Chinese Translators Journal 2: 3-10.

Wang Xiangyuan (2016) "The Thinking behind Fan 翻 and $Y i$ 译: Construction of the Concept of Translation in Ancient China" 翻、译的思想一一中国古代翻译概念 的建构. Social Sciences in China 2: 138-156.

Wen Hui (2015) "The Ontological Value and Prospects of Chinese Translation Theory" 中 国翻译理论的本体价值与展望. Shanghai Journal of Translators 4: 21-24.

Xie Tianzhen (2009) A Brief History of Translation in China and the West 中西翻译简史. Beijing: Foreign Language Teaching and Research Press.

Xing Jie (2014) "A Review of Traditional Chinese Translation Theory: Studies of Name Translation" 描写及其超越——《中国传统译论: 译名研究》评介. Chinese Translators Journal 6: 44-47.

Xu Jun, Mu Lei (2009) "Translation Studies in China in the Past Three Decades (1978-2007)" 中国翻译学研究 30 年 (1978-2007). Journal of Foreign Languages 1: 77-87.

Xu Jun (2018) Translation Studies in China since the Reform \& Opening-up (1978-2018) 改革开放以来中国翻译研究概论(1978-2018). Wuhan: Hubei Education Press.

Zeng Lisha (2017) "Constructing a Systematic Study of Theoretic Categories of Translatology: An Inherited Development of the Translation Theory" 论翻译学理论 研究范畴体系的拓展一一兼论传统译学理论的继承与发展. Foreign Languages in China 1: 90-96.

Zhang Boran, Zhang, Sijie (2001) "Towards the Establishment of Translatology in China" 翻译学的建设一一传统的定位与选择. Journal of Nanjing University 4: 87-94.

Zhang Sijie (2006) On the System of Categories in Chinese Traditional Translation Theories 中国传统译论范畴及其体系. Shanghai: Shanghai Translation Publishing House.

Zhao Wei (2014) "A Review of the Studies of Traditional Chinese Translation Theory" 中 国传统译论研究综述. Journal of Xi'an International Studies University 2: 104-107.

Zhao Xiuming (1996) "The Studies of Translation Theory in China Reflected by the Publication of A Draft History of Chinese Translation Theory" 从《中国译学理论 史稿》的出版看我国的译论研究. Chinese Translators Journal 3: 35-37.

Zhu Guicheng (2005) "The Impossibility, Possibility, and Others of the Dialogue between Chinese and Western Translation Theories" 中西译论对话的不可能、 可能及其他. Foreign Language Education 1: 86-89. 
